\title{
Promoting Cooperative Learning In An Expository Writing Course
}

Karen Sanderson Cole, University of the West Indies, St Augustine, West Indies

\begin{abstract}
English for Academic Purposes is a compulsory one-semester course offered to first-year students at the University of the West Indies in St. Augustine, Trinidad. Its primary objective is to assist students in developing competency in the targeted expository strategies that are deemed necessary to meet the writing requirements of the tertiary level. During Semester 2 in 2009-2010, cooperative learning was introduced in both the lecture and tutorial sessions of the evening programme in an attempt to improve the learning outcomes among the registered adult students. This paper examines the impact of cooperative learning on these students in the context of the lecture and tutorial sessions as students worked toward the production of a credited expository assignment. Both qualitative and quantitative methods were used to assess student feedback through questionnaires, peer feedback, and group performance on the credited assignment. The study confirmed that clear guidelines, practical-based content, and multiple opportunities to practice are significant in maximizing cooperative learning opportunities. However, cooperative learning cannot completely militate against the individual or collective disadvantages of weak language skills.
\end{abstract}

Keywords: Cooperative Learning; Adult Learners; Expository Writing; Tertiary Level

\section{BACKGROUND}

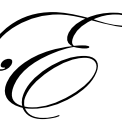
nglish for Academic Purposes has recently undergone a shift in the way in which the objectives of the course are taught and assessed. This shift has been undertaken as a result of several factors:

A push to more closely align the course with developments taking place within the general field of English for Academic Purposes

- A response to the mandate of the university's Board of Undergraduate Studies to reform and address the high failure rate and negative perception of the course by the university population at large

- $\quad$ The increasing number of students and limited teaching staff

All of these have pointed to the need to develop new and innovative ways of engaging students and monitoring their participation in the course. As part of the university's response, in 2008 the Department of Liberal Arts, which has specific responsibility for the course, made the decision to offer an evening version to cater to the largely working adult population interested in accessing university education between the hours of 5:00 pm and 10:00 pm.

Students typically interact with course content in several ways - through lecture sessions, tutorial sessions, independent study, interface with the online repository of information (which is known as myelearning), as well as tutor interaction. The use of cooperative work has been a significant aspect of the new thrust of the course.

Both full-time and part-time students attend the English for Academic Purposes evening university programme. These students are either from the Faculty of Social Sciences or the Faculty of Humanities and Education and range in age from 18 to 60. They are typically mature, working individuals. Reasons for enrolling in the evening programme range from job security to balancing demands of family life with the desire to excel academically. These characteristics fit the profile of the adult learner as observed in Nash (2007) and Collins (2004). 
The role of the facilitator/coordinator of the evening programme is to ensure that the appropriate content and support services are available. Cooperative learning seemed to offer a useful frame for addressing the issue of students' internalization of content within the course. Cooperative learning is defined by Dillenbourg (1999) as a learning context in which two or more people attempt to learn something together - a free exchange of ideas (Boxtel et al, 2000) with an emphasis on students' mastery of concepts taught (Good \& Brophy, 1990) and the elaboration of talk about the concepts involved in a particular field that encourages long-term retention (Bruffee, 1984, and Trimbur, 1989). Some researchers, like Gupta (2004), believe that cooperative learning also offers a more favorable learning environment for minority groups as well as mature students. These aspects of cooperative learning have important implications for the EAP course as they offer a way in which the contexts of learning - the lecture and tutorial - can be maximized to cater for the needs of the evening population.

The implementation of cooperative work has not been without its challenges. In the first semester (2009/2010) that cooperative work was implemented, students were given few guidelines about group formation aside from the fact that the group size was limited to 3-5 members and that all members had to be registered in the same tutorial group. Cooperative work was not a primary teaching strategy at the lecture sessions which the author taught, where the major concepts of the methods were presented through a combination of teacher-led PowerPoint presentations and presenter/student discussions. At the end of the semester, course evaluation questionnaires completed by students indicated dissatisfaction with group work and frustration with attempts to grasp the content of lecture sessions. Of the 87 students registered in Semester 1 during 2009-2010, student performance in the credited assignment indicated a $62 \%$ pass overall, with $2 \%$ receiving an A, $20 \%$ a B, and $32 \%$ a C. Based on feedback from the student evaluations, changes were implemented in Semester 2 during 2009-2010.

Of interest was whether a more structured cooperative learning approach to the teaching of expository writing would benefit students through the incorporation of more opportunities for practice of related skills within the lecture sessions, while simultaneously offering peer support as referenced in the literature on cooperative learning. The purpose is to introduce cooperative learning strategies within the lecture and tutorial sessions in the hope that in showing students how a cooperative environment could be fostered, they would then use these skills to work together to produce a credited expository essay.

This study looks at the introduction of collaborative work in the lecture and its formalization in the tutorial sessions. This study adapts some of the guidelines provided by Oakley, Felder, Brent \&Elhajj (2004) tailored to the needs of the target group - to organize structured groups in an effort to enhance the benefits of cooperative work.

\section{Statement of Problem}

Students of the Evening programme of English for Academic Purposes have difficulty in utilizing the expository strategies to write expository essays. This is evidenced through student feedback and through their performance on credited assignments. Current teaching and learning strategies used within the lecture and tutorial sessions have not been successful in improving their ability to develop competency in expository writing. Students need more opportunities for practicing the main concepts of writing so that they can produce better expository essays. Because of the time constraints placed on them by the course and their work situation, it was rationalized that students also need to learn how to utilize cooperative approaches to maximize learning opportunities. The purpose is to introduce cooperative learning strategies within the lecture and tutorial sessions in the hope that this will improve students' understanding of the methods which will, in turn, be reflected in their expository essays. Because these are primarily working adult students, their feedback on the process is also important in assessing whether the changes are helping them to achieve course goals.

\section{RESEARCH OBJECTIVES}

This study aims to determine the following:

1. How can cooperative learning be used to enhance students' understanding of expository methods in lecture sessions?

2. How do students perceive their experience of cooperative work to produce an expository essay? 
3. How has the incorporation of cooperative work impacted students' performance in the production of credited assignments?

4. What are the implications of cooperative learning as a strategy for teaching expository writing in English for Academic Purposes?

\section{LITERATURE REVIEW}

\section{Developing student competence in English for Academic Purposes}

In the field of English for Academic Purposes, the emphasis is on developing students' competence in expository writing. At the University of the West Indies in St Augustine, students enrolled in the course are typically required to write an expository essay, select an appropriate expository strategy (analysis by division, classification; process, comparison and contrast) and utilize grammatical and other language skills suitable to their purpose. Using a process approach to developing these skills, writing comprises the selection of a topic, generation of ideas, writing of drafts, and production of a final product. There is a current focus within the field, to develop writing within a communicative, task-based, collaborative frame (Raimes, 1991; Chen, 2003; and Hutchinson $\&$ Waters, 1984). This approach may favor adult learners in two main ways: 1) multiple peer perspectives on writing benefits learners who have been out of the educational system for awhile and need more time to develop the requisite skills and2) it is also generally accepted that the development of meaningful language skills should take place in a context that is pertinent to students' real-life applications (Olaofe, 1994, and Dudley-Evans, 1991). This means that learners' prior experiences or current working needs can be utilized to help them see how the required skills can benefit them in their immediate circumstances - a concern of the adult learner.

For adults who are autonomous and independent, course material must be accompanied by clear rubrics that explicitly state teacher expectations and allow learners to be able to self-regulate their performance (Andrade \& $\mathrm{Du}, 2008$ ). Creating opportunity within the course for quality feedback helps to encourage motivational beliefs and self-esteem - also important to adult learners - and to close the gap between current and desired performance (Nicol \& Macfarlane-Dick, 2006). These are also core features of quality academic environments listed by Chickering and Gamson (1987) in their landmark study on undergraduate teaching.

\section{Characteristics of the Adult Learner}

Many of the students registered in the Evening University Programme are different from their day counterparts in crucial ways. Cercone (2008) draws on the work of Knowles (1989), Merriam (1991), and Lieb (1991) and identifies characteristics of the adult learner that have direct implications for the way meaningful instruction is organized in the learning environment:

- $\quad$ Adults are independent and have a wealth of life experience.

- $\quad$ Adults are goal-oriented and need to see how new knowledge relates to their immediate goal.

- $\quad$ Adults are internally motivated, so self-reflection is an important aspect of their learning.

Each of these features has implications for the organization of learning activities to reach this target group. The independence of adults means that they need to be actively involved in the learning process. Helping them to make links between their previous experience and the new knowledge is an important step in helping them to retain new information longer and to compensate for the memory loss that is a normal part of aging (Cercone, 2008). Additionally, by making the objectives of the learning environment clear, instructors help the adult learner to develop a personal sense of relevance of the activity to their own learning.

\section{The Role of the Lecture Method in Higher Education}

Choosing a structure to develop expository writing skills in the adult learner must also take into consideration the modes of instruction available within the context. Within the tertiary environment, the lecture method continues to be a primary mode of managing large classes (Finkel, 2000). There are definite benefits to the lecture format. It offers a means of managing an increased number of students, increased workload of faculty and 
standardized delivery of content (Carpenter, 2006, and Bligh, 1998). Studies have shown that lectures may assist students in fact recall (de Carprariis, Barman \& Magee, 2001), but Johnson, Johnson \& Smith (1991) have observed that the lecture method assumes the homogeneity of the student population - that they all have the same level of note-taking skills and learning styles. This assumption may not be to the advantage of many learners. The lecture method has also been associated with passivity, short-term learning, low time on task and poor mastery of content (Bruffee, 1984, Cooper \& Robinson, 2000, and Finkel, 2000). However, the chief disadvantage of the lecture method may indeed be that students may have to wait weeks to practice course-related skills or demonstrate understanding and receive feedback (Cooper \& Robinson, 2000). This ability to incrementally practice writing skills is crucial to developing mastery within an expository context.

Within the tertiary-level environment, the challenge for the institution is not encouraging the adult learner to take responsibility for learning as much as providing the optimum conditions for that learning to take place. One of the challenges of learning institutions is thus to maximize the advantages of the lecture and still achieve learning objectives. The lecturer has a key role to play as motivator/empowerer of learning (Hall, 1996). There are specific techniques that can be employed within large lecture halls to help lecturers achieve these aims and improve student learning outcomes that can be applied to the adult learner (Suntherland \& Bonwell, 1996; Carbone, 1998, and Cooper \& Robinson, 2000). "Small-group inquiry and reflection" (Cooper \& Robinson, 2000, p. 6) is an important strategy in moving knowledge into long-term memory where it can be permanently retained (Johnson, Johnson, \& Smith, 1991, and Carbone, 1998).

\section{A Cooperative Approach to Developing Essay-writing Skills}

Cercone (2008) observes that although adult learners are characterized as independent, the reality is that some may need more structure than others to help them achieve their goals. A review of the literature reveals that cooperative learning is a significant strategy in promoting student learning and that this strategy has been usefully employed in developing essay writing skills and managing small group activity sessions in large halls. The terms 'collaborative', 'co-operative', and 'peer learning' are often used interchangeably within the literature to define a learning context in which two or more people attempt to learn something together (Dillenbourg, 1999) and exchange ideas (Boxtel et al, 2000). Within this environment, there is an emphasis on students' mastery of concepts taught (Good \& Brophy, 1990) and the elaboration of talk about the concepts involved in a particular field which encourages long-term retention (Bruffee, 1984, and Trimbur, 1989). Cooperative learning would therefore seem to offer a workable framework for addressing the needs of the adult learner precisely because it promotes cooperation rather than competition and respect for the varied experiences and backgrounds of participants (Boud, Cohen \& Sampson, 1999). As such, providing opportunities for students to think and talk among themselves about the writing requirements makes the actual writing process itself less burdensome (Bruffee, 1984).

Within the EAP environment, promoting a cooperative environment has to take into account the two contexts in which learning is promoted - the lecture and the tutorial. Biggs (1999) believes that the increasing number and diversity of the university population today have negatively impacted the usefulness of the traditional lecture and tutorial. More active learning strategies are therefore necessary to increase the benefit of these contexts for students. Involving students in a peer learning community improves their chances for success (Brookfield, 1999, and Bruffee, 1984). Incorporating discussion activities through Think/Pair/Share and Case Studies, for example, helps students develop informed understandings and improve their overall attitudes (Herreid, 2006, and Mazur, 1997). Practicing writing among peers is also another means of improving student writing skills (Hyashi, 2005).

Within the tutorial setting of EAP at St Augustine, while there are opportunities for students to brainstorm ideas and receive feedback on written drafts, Semester 1 feedback on cooperative learning has indicated a clear need for the provision of a structured approach to cooperative work that governs interaction and assessment. The necessity of these is also borne out by research done by Cercone (2008) and Oakley, Felder, Brent, \& Elhajj (2004) which underscore the importance of instructor-organized student interaction.

The instructor plays a crucial role in the organization of the framework for cooperative learning. Pointing to research done by Fiechtner \& Davis (1992), Obaya (1999), and Oakley, Felder, Brent, \& Elhajj (2004), note that students report having more successful team experiences with instructor-organized, rather than individual-organized, 
groups. Further, they argue that instructor-organized groups minimize tendencies to cheat within groups -'our personal experience is that... pre-existing relationships between students with a common corner-cutting mindset can reinforce the belief within a group that 'it's okay - everybody does it' (p. 11).

Structuring cooperative work means careful organization of the process. Oakley et al (2004) provide a detailed guide that covers the material to be used in the first class, which addresses the following: 1) different types of personality types likely to be found in the average group and strategies for dealing with them; 2) a getting-toknow-you questionnaire that requires information about the interests and time availability of the individual members of the group that the instructor can then use to assign groups; 3 ) the maximum number of members per group (3-4 for best interaction); and 4) peer assessment and evaluation forms for monitoring progress within the group. Groups are also provided with a format for organizing team meetings and team rules.

While Oakley et al (2004) are not unique in their advocacy for instructor-organized groups, Rafiq \& Fullerton (1996), Goldfinch \& Raeside (1990), and Goldfinch (1994) all offer a framework for group selection and organization, which are all conceived for the technical or engineering field. Oakley et al (2004) provide a guide that can be easily amended to the language writing environment. Especially useful are the activities for the first class which encourage students to reflect on their previous group experiences and write about them as well as offer guidelines for addressing problems that arise when members do not pull their weight. A peer evaluation form that is submitted at the end of the targeted exercise provides valuable data as to the internal workings of the group and the skills learned during the process.

To summarize, the available literature thus shows that to develop mastery of expository writing in adult learners, the following features need to be taken into account: 1) the utilization of appropriate frameworks to teach the targeted skill, 2) clear objectives and multiple opportunities for practice and feedback, and 3) an understanding of the specific needs of the learner and how the learning contexts can be maximized. One constellation of strategies that can be usefully considered is cooperative learning. Keen attention to strategies for organizing the cooperative learning process and instructor support can help students achieve mastery of the targeted skill.

\section{METHODOLOGY}

\section{Teaching context}

An average of 100 students attended each two-hour lecture session in the evening university's offering of English for Academic Purposes. Four of the 12 lecture sessions were devoted to developing support skills for expository writing (paragraph development, formulating an outline) and six to a specific expository technique (Analysis by Division, Classification, Comparison and Contrast). For the lecture format, the presenter used a combination of PowerPoint slides and an active learning strategy, such as think/pair/share, small group discussion, case study, and small group writing and feedback.

Each one-hour tutorial session catered to an average of 20 students and they chose tutorial sessions based on their personal availability. Following criteria set by Oakley et al (2004), students were placed into instructororganized groups of three to four members and they were encouraged to establish written group rules and a timetable for completing the assignment.

\section{Data Collection}

Both quantitative and qualitative means were used to assess students' cooperative efforts in the lecture and tutorial contexts. In week nine of the lecture sessions, students completed a lecture evaluation questionnaire which consisted of 10 open-ended questions that were designed to elicit information on students' perception of knowledge of methods covered in lecture sessions, student confidence in their level of mastery, the usefulness of lecture sessions in relation to course content, and specific areas that remained unclear after the course.

Peer evaluation sheets were collected in week 10. Each group was given a copy of the "Peer Rating of Team Members" sheet provided by Oakley et al (2004) which requires that group members evaluate each other 
using both a rating guide and a qualitative comment. The rating scale ranged from "No show-No participation at all" to "Excellent - consistently carried more than his/her fair share of the workload". The commentary section required students to make an evaluative comment on any aspect of the peer member's performance. These sheets were collected with the submission of the credited essay.

Students were given two opportunities to submit their preliminary drafts for feedback. Data on student performance in the final credited essay were collected in week 10. A numerical mark and a letter grade were assigned to each group's performance.

\section{Data Analysis}

Content analysis, using a coding scheme adapted by Dewiyanti et al (2007), was used to analyze student responses to the effectiveness of cooperative approaches to expository writing. For clarity of analysis, both the lecture and tutorial sessions were analyzed separately. In the lecture session, responses were grouped according to three broad categories - content, barriers (to understanding), and social. The content category coded knowledge of different expository methods. Barriers referred to anything that distracted from interaction with content and social to the experience of group interaction, as well as tutor interaction within the course. A positive or negative rating was applied to both categories. For each sub-category, the number of students from the questionnaires collected was noted and the corresponding percentage of the overall data was recorded.

To analyze the feedback from the tutorial sessions, the following dimensions were used:

- Regulation - activities related to coordinating activities of learners

- $\quad$ Consensus - activities or practices that gained group approval

- $\quad$ Conflict - responses to issues of disagreement that arose within the group

- $\quad$ Application - the manipulation of content

- Social- code information related to group interaction

A positive or negative rating was applied to this category. For each sub-category, the number of students from the questionnaires collected was noted and the corresponding percentage of the overall data recorded.

\section{FINDINGS}

\section{Plenary}

The plenary questionnaire was used to gauge students' perceptions of the contribution of the plenary sessions to grasping the content of the course and to assess what specific strategies they felt were particularly useful. Thirty-one (31) students provided feedback on the plenary questionnaire. The responses are summarized in Table 1.

\section{Tutorial}

Sixty-four students, representing 19 groups, returned the peer assessment forms. Table 2 collates the numbers and percentages of those who provided feedback relevant to the specific categories. Responses were recounted if they fit into more than one category.

\section{Student Performance}

Graph 1 summarizes student performance on the final credited essay collected in week 10. The assignment was valued at $22 \%$. 
Table 1: Coding Scheme to Assess Unstructured Group Interaction

\begin{tabular}{|c|c|c|c|}
\hline Dimension & $\begin{array}{l}\text { Category } \\
\end{array}$ & Number & $\%$ \\
\hline Content & $\begin{array}{l}\text { Knowledge gained of different expository methods } \\
\text { - Analysis by division } \\
\text { - Cause and Effect } \\
\text { - Comparison and Contrast } \\
\text { - } \quad \text { Process Analysis } \\
\text { - Classification } \\
\end{array}$ & $\begin{array}{c}12 \\
17 \\
14 \\
9 \\
11\end{array}$ & $\begin{array}{c}38.7 \% \\
54.8 \\
45.1 \\
29 \\
35.4\end{array}$ \\
\hline Barriers & $\begin{array}{l}\text { Insufficient time } \\
\text { Pace of class too fast/too slow } \\
\text { Methods still not understood } \\
\text { - Analysis by division } \\
\text { - Cause and effect } \\
\text { - Comparison and contrast } \\
\text { - Process analysis } \\
\text { - classification }\end{array}$ & $\begin{array}{l}0 \\
4 \\
8 \\
2 \\
2 \\
4 \\
7\end{array}$ & $\begin{array}{c}0 \\
12.9 \\
\\
25.8 \\
6.45 \\
6.45 \\
12.90 \\
22.5\end{array}$ \\
\hline Social & $\begin{array}{l}\text { Group interaction } \\
-\quad \text { positive } \\
\text { - negative } \\
\text { Interaction with tutor } \\
\qquad \quad \text { positive } \\
\text { - negative }\end{array}$ & $\begin{array}{c}4 \\
1 \\
\\
14 \\
4\end{array}$ & $\begin{array}{c}12.9 \\
3.2 \\
\\
45.1 \\
12.9\end{array}$ \\
\hline
\end{tabular}

Table 2: Results of Coding Scheme to Assess Unstructured Group Interaction

\begin{tabular}{|l|l|c|c|}
\hline \multicolumn{1}{|c|}{ Dimension } & \multicolumn{1}{|c|}{ Category } & Number & \% \\
\hline Regulation & Monitoring working procedure & 36 & 56.2 \\
& Monitoring work in progress & 34 & 53.1 \\
& Monitoring participation & 33 & 51.5 \\
\hline Consensus & Reaching consensus in the group & 42 & 64.6 \\
\hline Conflict & Conflict & 16 & 25 \\
\hline Application & Manipulation of content & 44 & 32.8 \\
\hline Social & Group interaction- positive & 6 & 68.7 \\
& -negative & 15 & 9.3 \\
& -mixed & & 23.4 \\
\hline
\end{tabular}

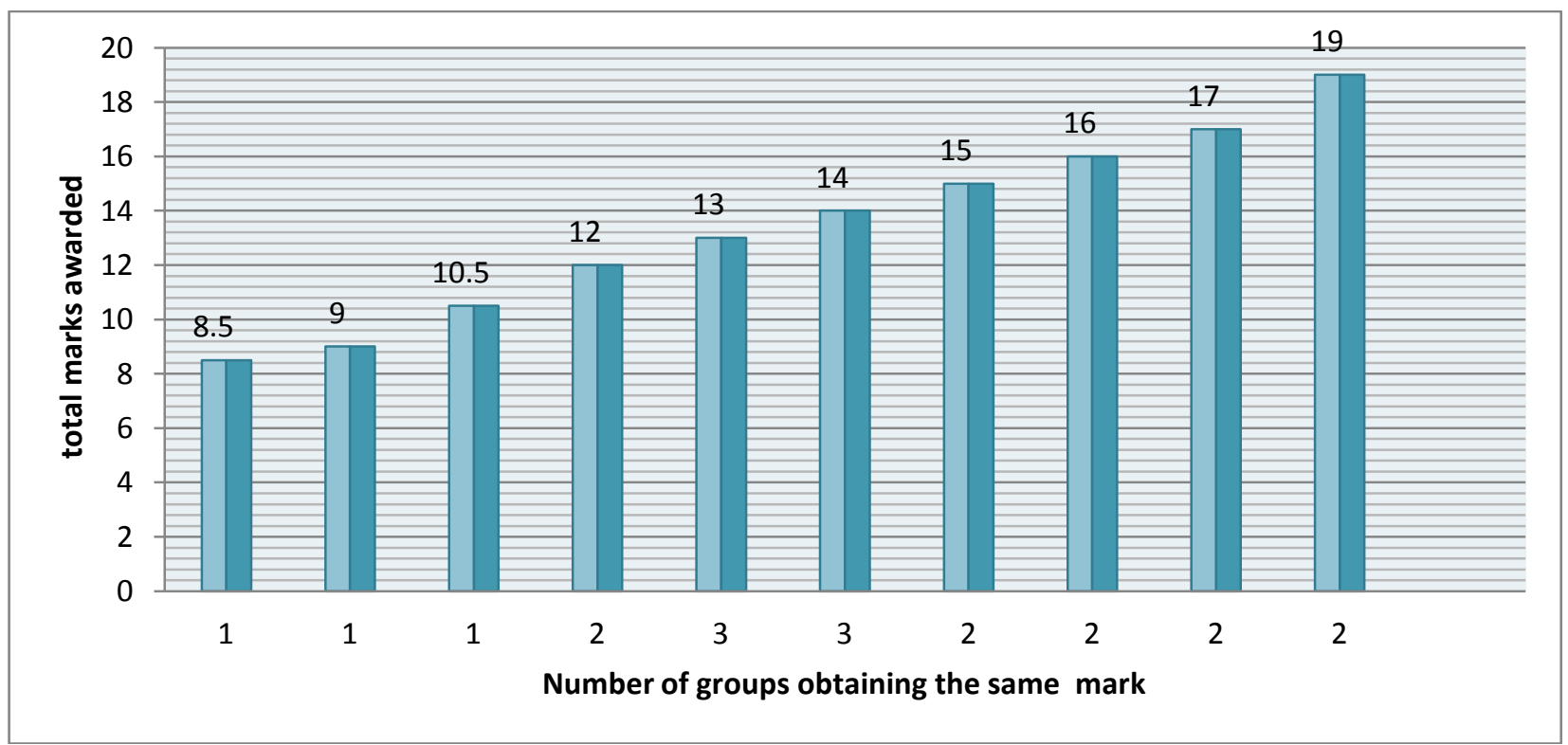

Graph 1: Student Performance on Final Credited Essay 


\section{DISCUSSION}

The aim of this study was to explore the significance of using cooperative learning strategies to enhance students' understanding of expository methods in lecture sessions, students' perceptions of their experience of cooperative work, the impact of cooperative strategies on students' performance, and the implications for cooperative learning for teaching expository writing in English for Academic Purposes.

1. How can cooperative learning be used to enhance students' understanding of expository methods in lecture sessions?

Cooperative learning, which involves students in group exercises, can be effectively used to assist students in understanding expository methods once the content is practical-based, relevant to students' own experiences, and offers immediate opportunity for practice. This opportunity to practice is important in developing mastery (Cooper \& Robinson, 2000). The significance of practice was confirmed by students' own responses to the lecture questionnaire - "the chance to apply the knowledge immediately", "the inclass questions to work in groups", and the "interactive" nature of the class.

Fifty-four percent of the students felt that group work within the lecture was significant in helping them to understand the method of Cause and Effect, $45 \%$ of Comparison and Contrast, and 38\% of Analysis by Division. The difference in responses among methods may have been influenced by the specific learning activity employed. For example, a case study approach was used with Cause and Effect analysis. The case was drawn from students' own experiences within the course and there was a high level of participation and enjoyment of this particular activity.

2. How did students assess their experience of cooperative work in structured groups?

In terms of regulation, the majority of students (56\%) felt that the groups worked well in monitoring participation of the individual members in the production of the credited assignment. The structured assignation of roles within the groups seemed to increase students' sense of personal responsibility for participation. Students commented that the group leader performed an important function in "show (in) commitment and calmness during stressful times"; "set (ting) deadlines"; and "in "us(ing) previous experience to guide (the) group assignment". The rating of individual members showed that some groups were more effective in working together than others. Half of the students rated the individual contribution of members as "very good", while the other $50 \%$ was equally divided between "excellent" and "mixed".

Manipulation of content was an area in which students commented positively on the contributions of individual members. They cited the opportunity within the group "to discuss ideas and opinions" as useful. The literature on cooperative learning emphasizes the importance of this (Bruffee, 1984, and Trimbur, 1989), which, in turn, seemed to build students' confidence in approaching the assignment. Groups also benefited from the opportunity to bring past experiences into the learning context (Olaofe, 1994, and Dudley-Evans, 1998). For example, the experience of repeaters was seen as an advantage to the other members in the preparation of the final assignment.

Structuring the groups seemed to help students most significantly in terms of regulation and consensus. Students commented positively on the members "working as a team", "communicating regularly" and "being cooperative". However, these criteria also became the sources of conflict within groups. Lack of attendance at meetings was the biggest area of conflict; $62 \%$ of students cited this as a major factor. Personality issues were a problem in $31 \%$ of the groups, followed by lack of cooperation (25\%), lack of communication (12.5\%), and unwillingness to accept criticism (12.5\%).

3. How has the incorporation of cooperative work impacted students' performance in the production of credited assignments? 
Fifty-eight percent of the class scored over $64 \%$ of the maximum allotted marks of 22. Sixteen groups (16) or $84 \%$ percent of the class scored in excess of 50\%. The average score on the credited assignment was 14 marks or 64\%. Eight groups scored less than this average, and 11 groups scored approximately $64 \%$ and above. Only three of the 19 groups, or $16 \%$ of the class, scored less than $50 \%$ on the credited expository essay. Cooperative work would therefore appear to have some positive impact on students' overall performance. Students who scored less than the average mark were hampered by weak language skills in terms of grammatical and expression competence rather than a lack of understanding of the method and demands of the question.

4. What are the implications of cooperative learning as a strategy for teaching expository writing in English for Academic Purposes?

There are significant implications for practice within the course. Cooperative learning provides a strategy for getting students to engage in a more practical way with the content of exposition through discussion, application, and interaction with peers. This interaction is important, particularly for adult students whose work, and family commitments may negatively impact on their ability to get the necessary practice. Student commentary, as cited earlier, indicated an appreciation of the opportunity to practice the skills "right away" within the lecture and the interaction as positive aspects of cooperative activity. Not everyone was impressed, however. Some students wrote that they "never wanted to do group work again" because there were individuals who did not adequately shoulder their responsibilities. Some students admitted to having a personal preference for working alone.

Student performance on the credited essay also highlighted another issue. While cooperative work has definite benefits for helping students to grasp and practice the general concepts of the course, there are other factors that impact group performance. In an expository writing course, students also need assistance in strengthening their grammatical skills. Even though structured cooperative work encourages group heterogeneity in groups where a significant proportion of members have weak grammatical skills, a firm grasp of the expository method alone will not help them to achieve the required level of mastery. Cooperative work will therefore have to be supported by additional services to cater for individual remediation.

Group activities, especially in the plenary session, demand a lot of prior preparation from the lecturer. There is a constant challenge to source information that can be turned into a specific expository activity and at the same time keep students interested and focused on the task. It is also evident that despite the structure provided in the tutorial setting for the production of the assignment, cooperative learning cannot be left to run on its own. Constant monitoring is necessary to ensure its success.

\section{CONCLUSION}

Passive involvement with course content, which is usually associated with the lecture method, does not provide the learning opportunities students need to inculcate the kind of deep learning necessary for long-term retention (Bruffee, 1984). In a context where it seems that fewer students enter the tertiary environment with the desired level of competence, cooperative approaches within lecture sessions help to give students the opportunities to develop and practice the necessary skills. Too often though, sufficient structures are not in place to help students access the benefits of cooperative learning. As Oakley et al (2004) point out, "students are not born with project management, time management, conflict resolution, and communication skills required for high performance teamwork" (p.9).

With regard to the production of a specific assignment, structured measures are useful in keeping students organized and focused on the task and minimize some of the traditional problems associated with group work. There was a modest increase at the end of the course in the percentage pass - $66 \%$ compared to $62 \%$ of the previous semester. Cooperative learning is unfortunately not a panacea for all ills. It cannot completely militate against the individual or collective disadvantages of a group of individuals with weak language skills. Further research is necessary to determine what additional support structures are necessary to enhance the benefits of cooperative work. 


\section{AUTHOR INFORMATION}

Karen Sanderson Cole is currently coordinator of the English Language Foundation Programme at the University of the West Indies, St Augustine both face to face and distance modes. She has also lectured in other university level courses in the areas of Linguistics and Literature. A graduate of the University of the West Indies, she holds a Bachelor's degree in History, Literature and Language, and a M.Phil in Literatures in English. She is also the holder of a post graduate diploma in Education. She recently completed an MHEd in Tertiary Teaching and Learning and is presently pursuing a Phd in Caribbean Literature. E-mail: Karen.sanderson-cole@sta.uwi.edu.

\section{REFERENCES}

1. Andrade, H., \& Du, Y. (2007). Student responses to criteria referenced self- assessment. Assessment and Evaluation in Higher Education, 32(2), 159-181.

2. Biggs, J. (1999). What the student does: Teaching for enhanced learning. Higher Education Research \& Development, 18, 57-75.

3. Bligh, D. (1998). What's the use of lectures? Wiltshire: Cromwell Press.

4. Boud, D. (1989). The role of self-assessment in student grading. Assessment and Evaluation in Higher Education, 14(1), 20-30.

5. Boud, D., Cohen, R., \& Sampson, J. (1999). Peer learning and assessment. Assessment and Evaluation in Higher Education, 24(4), 413-426.

6. Boxtel, C.V., Van de Linden, J., \& Kanselaar, G. (2000). Collaborative learning tasks and the elaboration of conceptual knowledge. Learning Instruction, 10, 311-330.

7. Brookfield, S. D., \& Preskill, M. S. (1999). Discussion as a way of teaching: Tools and techniques for democratic classrooms. San Francisco: Jossey-Bass.

8. Bruffee, K. (1984). Collaborative learning and the conversation of mankind. College English, 46 (7), 635652.

9. Cooper, J., \& Robinson, P. (2000). The argument for making large classes seem small. New Directions for Teaching and Learning, 81, 5-16.

10. Carbone, E. (1998). Teaching large classes: Tools and strategies. Thousand Oaks, London: Sage Publications.

11. Carpenter, J. (2006). Effective teaching methods for large classes. Journal of Family \& Consumer Sciences Education, 24(2), 13-23.

12. Cercone, K. (2008). Characteristics of adult learners with implications for online learning design. AACE Journal, 16(2), 137-159.

13. Chickering, A \& Gamson, Z. (1987). Seven principles for good practice. American Association for Higher Education Bulletin. Retrieved December 8 2010, from http://honolulu.hawaii.edu/intranet/committees/FacDevCom/guidebk/teachtip/7princip.

14. Chen, C. (2003). A constructivist approach to teaching: Implications in teaching computer networking. Information Technology, Learning, and Performance Journal, 21(2), 17-27.

15. Collins, J. (2004). Education techniques for lifelong learning: Principles of adult learning. RadioGraphics, 24, 1483-1489. Retrieved March 12, 2008, from http://radiographics.rsnajnls.org/cgi/content/full/24/5/1483

16. De Caprariis, P., Barman, C., \& Magee, P. (2001). Monitoring the benefits of active learning exercises in introductory survey courses in science: An attempt to improve the education of prospective public school teachers. The Journal of Scholarship of Teaching and Learning, 1(2), 1-11.

17. Dillenbourg, P. (1999). What do you mean by collaborative learning? In P. Dillenbourg (Ed.), Collaborative learning: Cognitive and computational approaches (pp. 1-19). Oxford: Elsevier.

18. Dewiyanti, S., Brand-Gruwel, S., Jochems, W., \& Broers, N. (2007). Students experiences with collaborative learning in asynchronous computer-supported collaborative learning environments. Computers in Human Behaviour, 23, 496-514. Retrieved October 5, 2010, from http://www.elsevier.com/wps/find/journaldescription.cws_home/759/description\#description

19. Johns, A. M., \& Dudley-Evans, T. (1991). English for specific purposes: International in scope, specific in purpose. TESOL Quarterly, 25(2), 297-314. Retrieved August 12,2010,from www.jsor.org/stable

20. Entwistle, N., \& Ramsden, P. (1983). Understanding student learning. London: Croom Helm.

21. Finkel, D. L. (2000). Teaching with your mouth shut. Portsmouth, NH: Boynton /Cook Publishers. 
22. Goldfinch, J. (1994). Further developments in peer assessment of group projects. Assessment and Evaluation in Higher Education, 19(1) 29-35.

23. Goldfinch, J., \& Raeside, R. (1990). Development of a peer assessment technique for obtaining individual marks on a group project. Assessment and Evaluation in Higher Education, 15(3), 210-231.

24. Good, T., \& Brophy, J. (1990). Educational psychology: A realistic approach. New York \& London: Longman.

25. Gupta, M. L. (2004). Enhancing student performance through cooperative learning in physical sciences. Assessment and Evaluation in Higher Education, 29(1), 63-73.

26. Hativa, N. (2000). Teaching for effective learning in higher education. Kluwer Academic Publishers: Dodrecht.

27. Hall, C. (1996). Key teaching roles of a university lecturer and their integration into the quality systems of a New Zealand university. Assessment \& Evaluation in Higher Education, 21(2), 109-120.

28. Hayashi, C. (2005). Scaffolding the academic writing process: A focus on developing ideas. Paper presented at Lifelong Learning: Proceedings of the $4^{\text {th }}$ Annual JALT Pan -SIG Conference. Tokyo, Japan: Tokyo Keizai University.

29. Hiemstra, R. (1991). Aspects of effective learning environments. New Directions for Adult and Continuing Education, 50. Retrieved March 12, 2008, from http://www-distance.syr.edu/ndacelech1.html

30. Herreid, C. F.(2006). Using case studies to teach science. Action Bioscience. Retrieved August 12, 2010, from www.actionbioscience.org/education/herreid.html

31. Hutchinson, T., \& Waters, A. (1984). How communicative is ESP? ELT Journal, 2, 108-113.

32. Johnson, D. W., Johnson, R.T., \& Smith, K. A. (1991). Active learning: Cooperation in the college classroom. MN: Interaction Book Company.

33. Mazur, E. (1997). Peer instruction: A user's manual. New Jersey: Prentice Hall.

34. Nicol, D., \& Macfarlane-Dick, D. (2006). Formative assessment and self-regulated learning: A model and seven principles of good feedback practice. Studies in Higher Education, 31(2), 199-218.

35. National Research Council. (2000). How people learn: Brain, mind, experience, and school. Washington: National Academy Press.

36. Oakley, B., Felder, R., Brent, R., \& Elhajj, I. (2004). Turning student groups into effective teams. Journal of Student-Centred Learning, 2(1), 9-26.

37. Olaofe, I. (1994). Testing English for academic purposes (EAP) in higher education. Assessment and Evaluation in Higher Education, 19(1), 37-48.

38. Rafiq, Y., \& Fullerton, H. (1996). Peer assessment of group projects in civil engineering. Assessment \& Evaluation in Higher Education, 21(1), 69-81.

39. Raimes, A. (1991). Out of the woods: Emerging traditions in the teaching of writing. TESOL Quarterly. 25(3), 407-430.

40. S. Nash. (2007, June 11). Inside eLearning: Adult online learners: At risk? [Web Log Comment]. http://community.elearners.com/blogs/inside_elearning/archive/2007/06/11/Adult-Online

41. Suntherland, T., \& Bonwell, C. (1996). Using active learning in college classes: A range of options for faculty. San Francisco: Jossey-Bass.

42. Trimbur, J. (1989). Consensus and difference in collaborative learning. College English, 15(6), 602-616. 
NOTES 